treatment have produced a tough and agile goat which can consume organic matter of almost any type. The sheep, mostly of the fat-tailed breed, are also very hardy. The camel, fortunately less common in the northern districts, eats what the goat cannot reach. No attempts have been made to estimate the permanent carrying capacity of the land, the number of animals grazed is limited only by drought, starvation and disease; and the vegetation is destroyed over large areas, which have become artificial deserts in spite of good climatic and geological factors. Soils were nearly everywhere excellent before they were removed by erosion. All other forms of damage fade into insignificance beside the destruction caused by grazing, though the process is accelerated by cutting and uprooting."

Yet there are still some who dispute that obvious factor on the globe, the man-made desert-both of the past, and those of more modern origin, and in the making.
Forestry problems of increasing magnitude and importance are many in the British Colonial Empire.

The welcome and wide-visioned Colonial policy recently announced by the Secretary of State offers, it may be hoped, opportunity that in the future continuity in a forest policy, duly drawn up and sanctioned, may be persisted in, whatever vicissitudes befall the Colonial budget; and, above all, that recognition should be accorded to the factor that the scheme for reservation of the forest areas in any Colony considered needful to its economic progress, the protection of its water supplies, etc., upon which the agricultural prosperity depends, should take precedence of other work. The policy, as laid down for Nigeria by the 1937 Committee, that foreshadowed in the Palestine Report, and those so often voiced for other Colonies, should now become practical politics in view of Mr. Malcolm Macdonald's masterly White Paper.

\title{
ECONOMIC PROBLEMS OF INDUSTRIAL SCIENTISTS
}

\begin{abstract}
A SERIES of regional conferences to discuss the economic problems of men of science and engineers employed in industry has recently been held in London, Liverpool and Manchester. Others are to follow, and it is intended that a national conference shall be held in the autumn in order to collate the information obtained at the regional conferences. The conferences are being organized by the Association of Scientific Workers, but many members of other professional organizations attended the meetings and took part in the papers and discussions. It is hoped that this collaboration will continue and increase as a result of the interest aroused.

The London regional conference, held on March 9, with Prof. F. G. Donnan in the chair, was opened by Mr. Hugh N. Linstead, with a general discussion on the place of the scientific worker in industry and on the role of professional organizations. He pointed out that, in view of the great importance of the role of the scientist in modern industry, the discrepancies between the salaries of scientists in industry as compared with those in administrative positions can only be rectified by scientists organizing themselves. Such an organization must protect the interests of the scientific worker, but be broad enough to consider the problems of the industry and the employer as well. In spite of the prejudice against trade unionism among professional workers, the trade unions play an essential part in industry, and both the scientist and the community suffer from lack of this type of organization among scientists.
\end{abstract}

This was followed by a paper by Mr. J. Stewart Cook on the question of salaries, increments, overtime, etc. His paper consisted of a factual analysis of the data available in these questions as they affect both graduate scientists and assistants, and was based on the results of a questionnaire sent out by the Association of Scientific Workers, and on data published by the Institute of Chemistry. He considers that salaries will only be uniformly adequate and satisfactory when scientists are organized on such a basis that they can and will refuse to take jobs below prescribed rates. He pointed to the good record of the British Association of Chemists in this respect, attributing its success to the policy of maintaining an appointments board, backed up by an unemployment scheme.

The rights of publication were discussed by Mr. H. T. Rhodes, and the question of holidays and opportunities for study by Mr. J. L. Pinder. The latter stressed the necessity for adequate holidays and opportunities to attend scientific lectures, if the scientist is to produce his best work. $\mathrm{He}_{\theta}$ is in favour of a 5-day week. The question of adequate time for study as well as for recreation is essential for assistants studying for degrees. He considers their position in this respect is often unsatisfactory.

The problems of the assistant were dealt with by Mr. R. Peter, himself an assistant. The assistant is faced with the double task of satisfying the employer by day and the examiner by night. The principal requirements of assistants are (1) standardization of working hours throughout industry, (2) standardization of wages based on some grading system of age and qualifications, (3) a definition of work expected on engagement and a limitation of this, in general, to technical matters, (4) allowance of adequate time for study and recreation and provision of financial assistance where necessary for the cost of study.

A paper was then given by Mr. F. W. Adams dealing with the legal side of scientific employment, in which he discussed the questions of contracts, of copyright and the right to seek alternative employment.

Prof. J. D. Bernal, in summing up, pointed out the similarities and the differences in the position of scientists in this War and that of 1914-18. Since 1918 the scientist and the laboratory have become an integral part of industry, but there has not been the development of organization of scientists which has occurred in other spheres of industry. Bad conditions for scientists mean a depression in productivity of industry. The increasing number of assistants entering the ranks of qualified scientists means that the whole range of the problem from assistant to directorate must be tackled, as an anomaly in any 
one section would be felt by all other sections of industrial scientists, and also by academic and Government employees. He considers that scientists as salaried workers require some type of trade union organization which would include organization of assistants. The details of such an organization would require special study, but the immediate consideration is the building up of organizations such as the Association of Scientific Workers and the British Association of Chemists.

The Liverpool Conference was held on March 4, and was opened by Mr. J. P. Lawrie with a general discussion of the questions involved. This was followed by a factual paper on assistants, their status and problems. A survey of contemporary professional organizations was then given. It was pointed out that a very large number of professional workers, such as teachers, medical men and journalists, are already organized in trade unions. In purely scientific fields the degree of organization is comparatively very low. The learned societies are precluded by their charters from activities affecting the economic conditions of their members, and the field is still open for vast development. The British Association of Chemists, with 2,000 members, has been registered as a trade union since 1920. The Association of Scientific Workers, with 1,500 members, is not now a trade union, but interests itself in economic activities. Mr. Lawrie then gave a survey of advertisements for scientific posts and a statistical analysis of the materiak collected regarding salaries was given. The position of women scientists was considered and the discrepancy in wages pointed out. It is realized that this question has increased in importance since the War began.
The Manchester Conference was held on March 16, with Prof. Willis Jackson in the chair. Prof. H. Levy, in opening the discussion, said that scientists are not brought up in an industrial atmosphere, and the idea of trade unionism is, consequently, foreign to them. He showed that the same forces operate with industrial scientists as with manual workers. $\mathrm{He}$ then analysed the different types of scientific work and discussed the impact of the War on science and on scientists. This was followed by a paper on basic salaries, increments, cost of living adjustments, etc. The question of contracts was the subject of the next paper, and the anomalies and lack of standardization was pointed out. After this, the problems of students were discussed, especially under the conditions of the War. The effect of conscription and the increase in the cost of living due to the evacuation of universities were dealt with.

The final papers dealt with the rights of publication and the problems of the laboratory assistant. In the latter, the main problems were considered to be: diversity of labour, lack of standardization, salaries, absence of status, promotion and unskilled labour, especially since the outbreak of war.

All three conferences were very well attended and were accompanied by lively discussion from the floor. The two salient features of the conferences were the realization of the growing role which the laboratory assistant takes in industrial science, and the feeling that the War is raising acute economic problems for scientists and an active organization is needed capable of protecting their interests.

A full report of the conferences will be given in the April-May number of the Scientific Worker, the organ of the Association of Scientific Workers.

\section{DRUG STANDARDS FOR INDIA}

$\mathrm{T}$ HE ambition of those enlightened practitioners of medicine in India who, under the leadership of Dr. Chopra, have sought for many years past to bring that country into line with the rest of the civilized world in the matter of standardized drugs now seems to be near achievement. A comprehensive measure providing for the uniform control of the manufacture and sale of drugs as well as the importation of drugs is now before the Legislative Assembly ; the introduction of such a Bill is, in itself, no small advance towards the desired goal, since the Bill is backed by resolutions from every one of the provincial legislatures empowering the central authority to pass an Act to regulate the nanufacture, distribution and sale of drugs throughout India. No such resolutions were necessary for the purpose of a measure to regulate the importation of drugs, but such limited control would fail to bring about the desired purpose, namely, to create a clean business in medical supplies in every province. It would be of little use to prohibit the importation of inferior drugs if there were no means of preventing the sophistication of imports or the domestic production of inferior preparations. The Bill, when it becomes law, will extend to the whole of India.

So far as imports are concerned, the Bill makes it an offence to import misbranded drugs, by which term is meant, briefly, drugs different from what they are represented to be by the labels on their containers. It specifically prohibits the importation of "any drug which is not of standard quality", and it is interesting to find that the standards with which compliance will be necessary are as follows: (1) proprietary medicines: the list of ingredients described on the label or the formula disclosed to the Central Drug Laboratory, as the case may be; (2) vaccines, sera, toxins and other biological products of a like nature : the standards maintained at the National Institute for Medical Research, London; (3) vitamins, hormones and analogous products : the standards maintained at the National Institute; (4) other drugs : the standards of identity, purity and strength specified in the latest edition either of the British Pharmacopoia or the British Pharmaceutical Codex or any other prescribed pharmacopœia, or adopted by the Permanent Commission on Biological Standardisation of the League of Nations. On the principle of what is "sauce for the goose is sauce for the gander", the part of the Bill which relates to domestic manufacture and to the sale and distribution of drugs is in effect the same as that which applies to the importation of drugs ; the standards to be complied with are identical in each case. 